\title{
Pengaruh Motivasi Terhadap Hasil Belajar Siswa SMK
}

\author{
Hendra Dani Saputra ${ }^{1 *}$, Faisal Ismet ${ }^{1}$, Andrizal ${ }^{1}$ \\ ${ }^{1}$ Jurusan Teknik Otomotif, Fakultas Teknik, Universitas Negeri Padang \\ * Corresponding author, e-mail: hendradani@ft.unp.ac.id
}

\begin{abstract}
Abstrak - Penelitian bertujuan untuk melihat pengaruh motivasi terhadap hasil belajar siswa. Rendahnya hasil belajar dapat dipengaruhi oleh dua faktor yaitu faktor yang berasal dari dalam diri siswa (faktor internal) dan faktor yang berasal dari luar diri siswa (faktor eksternal).Penelitian berfokus pada faktor internal yaitu motivasi belajar. Metode penelitian yang digunakan adalah penelitian deskriptif. Penelitian bertujuan melihat besarnya tingkat hubungan antara dua variabel yaitu motivasi belajar siswa dengan hasil belajar siswa.Teknik pengambilan sampel menggunakan teknik proporsional random sampling. Data penelitian didapat dari penyebaran angket yang diberikan kepada siswa. Hasil penelitian menunjukkan nilai koefisien korelasi penelitian sebesar 0,860 dengan $\alpha=0,05$ dan koofisien korelasi pada tabel $(r$ tabel $=0,349)$ sehingga $t$ hitung $>t$ tabel dengan $\alpha=0,05$. Hal ini menunjukkan motivasi belajar mempunyai hubungan yang positif dan signifikan dengan hasil belajar siswa.
\end{abstract}

Kata kunci : media pembelajaran flash flip book, pengembangan, valid dan praktis.

\begin{abstract}
The research aimed to see the influence of motivation on student learning outcomes. The low learning outcomes can be influenced by two factors: factors that come from within students (internal factors) and factors that come from outside the student self (external factors). Research focuses on the internal factors of learning motivation. The research method used is descriptive research. The study aims to see the level of relationship between two variables that is the students' learning motivation with student learning outcomes. Technique of sampling using proportional random sampling technique. Research data obtained from the questionnaire distributed to students. The result showed that the correlation coefficient value of research was 0,860 with $\alpha=0,05$ and correlation coefficient on table ( $r$ table $=0,349)$ so that $t$ count $>t$ table with $\alpha=0,05$. This shows the motivation to learn has a positive and significant relationship with student learning outcomes.
\end{abstract}

Keywords : learning outcomes, motivation

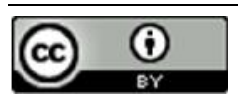

This is an open access article distributed under the Creative Commons 4.0 Attribution License, which permits unrestricted use, distribution, and reproduction in any medium, provided the original work is properly cited. @2018 by Author and Universitas Negeri Padang

\section{Pendahuluan}

Hasil belajar merupakan salah satu acuan terhadap keberhasilan dalam proses pendidikan. Hasil belajar dapat berupa kemampuankemampuan yang dimiliki siswa. Kemampuan ini didapat setelah melalui dan menerima pengalaman-pengalaman dalam proses belajar yang dilakukan siswa. Ketercapaian dan suksesnya sebuah proses pembelajaran dapat dilihat dari nilai hasil belajar yang diperoleh oleh siswa. Tinggi dan bagus nilai hasil belajar berarti proses pembelajaran telah sukses. Akan tetapi Rendahnya hasil belajar siswa menunjukkan tidak tercapai dan suksesnya proses pembelajaran. Rendahnya hasil belajar dipengaruhi oleh dua faktor, faktor internal ada dalam diri siswa dan faktor ekternal yang diluar dari siswa.
Dalam penelitian yang dilakukan berfokus pada faktor internal yaitu motivasi. Faktor ekternal seperti lingkungan, sosial ekonomi dan lain sebagainya diasumsikan tidak mempengaruhi, agar membatasi penelitian ini khusus pada faktor internal saja.

Dalam penelitian sebelumya yang dilakukan oleh Ahmad Arif, menunjukkan faktor internal dalam diri siswa yaitu minat yang menjadi salah satu penyebab rendahnya hasil belajar siswa. Hasil penelitian Ahmad arif menunjukkan hubungan minat siswa terhadap hasil belajar siswa memiliki hubungan yang positif dan signifikan.[1]. Penelitian yang dilakukan berfokus pada faktor internal lainnya yang mengakibatkan rendahnya hasil belajar. Adapun faktor internal yang akan diteliti yaitu motivasi belajar. 
Tim MKDK FIP UNP Padang (2005:68) menyatakan bahwa motivasi adalah suatu kondisi dari siswa untuk memprakarsai kegiatan, mengatur arah kegiatan itu dan memelihara kesungguhan.[2] Dengan adanya motivasi siswa menjadi sungguhsungguh dan giat dalam belajar. Proses pembelajaran yang dilakukan oleh siswa harus memiliki motivasi yang tinggi agar mudah mencapai hasil belajar yang diharapkan. Marta Eka Chandra dalam penelitiannya membuktikan bahwa dengan motivasi belajar yang baik dan tinggi akan memberikan hasil belajar yang baik pula. Dengan motivasi dalam belajar yang baik dan tinggi akan menghasilkan hasil belajar yang baik dan tinggi pula.[3]

\section{StUdi Pustaka}

\section{A. Belajar}

Kegiatan belajar merupakan kegiatan yang paling pokok dalam proses pendidikan . dalam proses belajar terdapat kegiatan-kegiatan belajar yang nantinya akan sangat mempengaruhi hasil atau output dari proses pendidikan. Kegiatan belajar dinyatakan dalam Oemar (2008: 154) adalah perubahan tingkah laku yang relatif mantap berkat latihan dan pengalaman [4]. Setelah proses belajar selesai dilakukan akan terjadi perubahan tingkah laku pada peserta didik. Hal ini dapat dilihat sebagai hasil belajar. hasil belajar merupakan hasil dari proses belajar berupa perubahan tingkah laku pada individu yang telah belajar, perubahan tingkah laku tersebut dapat dilihat pada bidang kognitif (pengetahuan), afektif (sikap), dan psikomotor (keterampilan) siswa ke arah yang lebih baik

\section{B. Hasil Belajar}

Hasil belajar dapat dijadikan acuan untuk mengetahui kelebihan dan kekurangan siswa dalam berbagai bidang studi atau mata pelajaran yang ditempuhnya, kemudian dapat diketahui seberapa jauh keefektifan proses belajar yang dilakukan dalam mengubah tingkah laku para siswa kearah tujuan pendidikan yang diharapkan. Pendidik memberikan penilaian kepada para siswa berupa perkembangan dan kemajuan dari pengetahuan, keterampilan, dan perubahan sikap yang di peroleh setelah siswa melakukan proses belajar.

Untuk mengetahui hasil belajar yang diperoleh oleh siswa maka dilakukan terlebih penilaian hasil belajar. Penilaian biasanya dinyatakan dalam bentuk angka, huruf, simbol ataupun kata-kata, yang tujuannya untuk mengukur sejauh mana penguasaan siswa terhadap apa yang telah dipelajarinya dengan menggunakan kriteria tertentu sebagai patokan atau acuan penilaian. Hasil belajar dipengaruhi oleh dua faktor yaitu berasal dari dalam diri siswa (intern) dan faktor yang berasal dari luar diri siswa (ekstern). Fokus penelitian pada faktor intern (faktor dalam diri siswa), sejauh mana memberikan pengaruh pada hasil belajar Adapun faktor-faktor intern antara lain intelegensi, perhatian, minat, bakat, motivasi, kematangan, dan kesiapan.Penelitian Andryvo menyatakan bahwa salah satu faktor intern dalam diri siswa yaitu minat menjadi faktor penyebab rendahnya hasil belajar siswa.[5]

\section{Faktor-Faktor yang mempengaruhi Hasil Belajar}

Faktor-faktor yang mempengaruhi hasil belajar tersebut dapat dijelaskan sebagai berikut:

a. Faktor Intern (dalam diri siswa)

1. Faktor jasmaniah, yaitu: faktor kesehatan dan cacat tubuh.

2. Faktor psikologis, yaitu: intelegensi, perhatian, minat, bakat, motif, kematangan, dan kesiapan.

3. Faktor kelelahan, yaitu: kelelahan jasmani dan kelelahan rohani.

b. Faktor ekstern (faktor luar diri siswa)

1. Faktor keluarga, yaitu: cara orang tua mendidik, relasi antara anggota keluarga, suasana rumah tangga, keadaan ekonomi keluarga, pengertian orang tua dan latar belakang kebudayaan.

2. Faktor sekolah, yaitu: metode mengajar, kurikulum, relasi guru dengan siswa, relasi siswa dengan siswa, disiplin sekolah, alat pelajaran, waktu sekolah, standar pelajaran, keadaan gedung, metode belajar dan tugas rumah.

3. Faktor masyarakat, yaitu: kegiatan siswa dalam masyarakat, mass media, teman bergaul, bentuk kehidupan masyarakat.

\section{Penilaian Hasil Pembelajaran}

Penilaian hasil belajar digunakan untuk mengetahui hasil belajar yang diperoleh oleh siswa. Hasil belajar ditandai dengan nilai yang diberikan kepada siswa. Ellizar (2009: 120) mengatakan bahwa "Evaluasi merupakan suatu proses penilaian atau hasil dari suatu proses penilaian untuk mengambil keputusan yang menggunakan seperangkat hasil pengukuran dan berpatokan kepada tujuan yang telah dirumuskan.[6] 
Penilaian hasil belajar dapat bagi menjadi tiga ranah:

1. Ranah kognitif

Berupa hasil belajar kemampuan intelektual atau berpikir.

2. Ranah Afektif

Berupa hasil belajar kemampuan perasaan, sikap dan kepribadian.

3. Ranah Psikomotor

Berupa hasil belajar kemampuan keterampilan.

Siswa SMK dituntut untuk memiliki kemampuan dalam ketiga ranah penilaian dalam proses pembelajaran yang dilakukan. Agar siswa menjadi siswa yang kaya intelektual, mempunyai kepribadian dan sikap yang mulia serta memiliki keterampilan yang handal pada bidang yang ditekuni.

\section{E. Motivasi Belajar}

Mengutip pendapat dari para ahli motivasi , motivasi diartikan sebagai suatu kondisi dari siswa untuk memprakarsai kegiatan, mengatur arah kegiatan itu dan memelihara kesungguhan dalam menjalani proses pembelajaran. Motivasi dapat diartikan sebagai salah satu energi yang mendorong siswa untuk terus giat, bersungguhsungguh dalam belajar. Komponen-komponen dasar motivasi meliputi beberapa aspek diantaranya kebutuhan, perilaku dan tujuan.

Ketiga aspek di atas perlu dimilki oleh setiap individu dalam hal ini seorang siswa dalam proses mencapai tujuan yang diinginkan yaitu hasil belajar yang tinggi dan baik. Motivasi dibagi kedalam dua jenis

1. Motivasi Primer

Motivasi yang didasarkan atas motif-motif dasar yang pada umumnya berasal dari segi biologis atau jasmani seseorang. Contoh motivasi primer: memelihara diri, mencari makan, melarikan diri, berkelompok, mempertahankan diri, rasa ingin tahu dan lainlain.

2. Motivasi Sekunder

Motivasi yang dipelajari oleh manusia sebagai pembentukan perilaku manusia dalam hubungan dengan lingkungan sosial

Sifat Motivasi

1. Motivasi Instrinsik

Motivasi dapat tumbuh dari dalam diri sendiri dan biasanya dikenal dengan motivasi internal

2. Motivasi Ekstrinsik

Motivasi yang muncul dari luar diri seseorang
F. Faktor - Faktor yang Mempengaruhi Motivasi dalam Belajar

Motivasi belajar dapat berupa motivasi intrinsik (yang terkandung dalam diri siswa (individu). dan motivasi ektrinsik dorongan terhadap perilaku seseorang yang ada di luar perbuatan yang dilakukan siswa). Walaupun tidak mutlak, penguatan dan pengembangan motivasi belajar siswa tersebut juga berada di tangan guru atau pendidik dan anggota masyarakat lainnya. Guru sebagai pendidik dan pengajar bertugas memperkuat motivasi belajar siswa di sekolah. Orang tua dan anggota masyarakat bertugas memperkuat motivasi belajar siswa di rumah dan dilingkungan secara berkesinambungan

Dalam pengembangan motivasi, banyak faktor yang mempengaruhinya, antara lain:

1) Cita-cita dan Aspirasi Siswa

2) Kemampuan Yang Dimiliki Siswa

3) Kondisi Jasmani dan Rohani Siswa

4) Kondisi Lingkungan Siswa

5) Unsur-unsur Dinamis Dalam Pembelajaran

6) Upaya atau Dorongan Guru Dalam Memotivasi

\section{METODE}

\section{A. Jenis Penelitian}

Penelitian ini merupakan penelitian deskriptif bersifat korelasional. Lufri menyatakan yang dimaksudkan untuk penelitian deskriptif bersifat korelasiona adalah penelitian yang dimaksudkan untuk mengetahui ada tidaknya hubungan antara dua atau beberapa variabel dengan teknik korelasi. [7] Total populasi sebanyak 33 orang siswa. Besar atau tingginya hubungan tersebut dinyatakan dalam koofisien korelasi.

\section{B. Teknik Pengumpulan Data}

Data akan diuji dengan uji prasyarat analisis dengan dua pengujian yakni Uji Normalitas dan Uji Linearitas. Lalu hipotesis statistik akan menggunakan Uji Korelasi dan Uji Keberartian Korelasi.

\section{Hasil dan Pembahasan}

Data hasil belajar menyebar dari nilai terendah 5,5 dan tertinggi 8,2 . Berdasarkan nilai tersebut didapat rata-rata (mean) $=6,831$, skor tengah $($ median $)=6,86$, skor yang banyak muncul (mode) $=6,738$, simpangan baku $=0,638$, rentangan (range $)=2,7$, keragaman $=0,4070$, serta skor total 219,1

Dari olahan data tersebut dapat dinyatakan bahwa data hasil belajar siswa berdistribusi normal 
dimana selisih nilai mean, median dan modus tidak melebihi standar deviasi.

\section{A. Uji Normalitas}

Analisis normalitas dari pengumpulan data angket motivasi belajar. Dilakukan pengujian dengan menggunakan rumus chi kuadrat dengan ketentuan jika $\chi^{2}$ hitung $<\chi^{2}$ tabel maka data berdistribusi normal .

Nilai chi kuadarat hitung untuk motivasi belajar sebesar 1,0653 dan chi kuadrat tabel sebesar 9,488 dengan taraf signifikan yang dipakai adalah 0,05. Gambar 1 menunjukkan histogram data motivasi belajar.

Analisis normalitas data hasil belajar siswa diuji dengan menggunakan rumus chi kuadrat dengan ketentuan jika $\chi 2$ hitung $<\chi 2$ tabel maka data berdistribusi normal. Nilai chi kuadarat hitung untuk variabel hasil belajar sebesar 7,4297 dan chi kuadrat tabel sebesar 9,488 dengan taraf signifikan yang dipakai adalah 0,05. Gambar 2 menunjukkan histogram data hasil belajar.

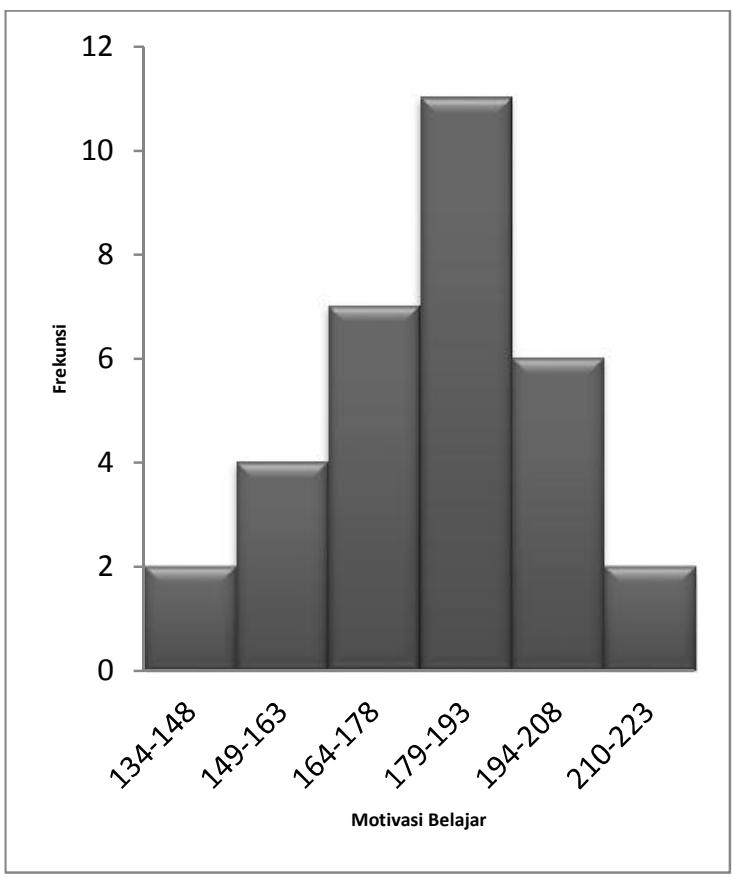

Gambar 1. Histogram Motivasi Belajar

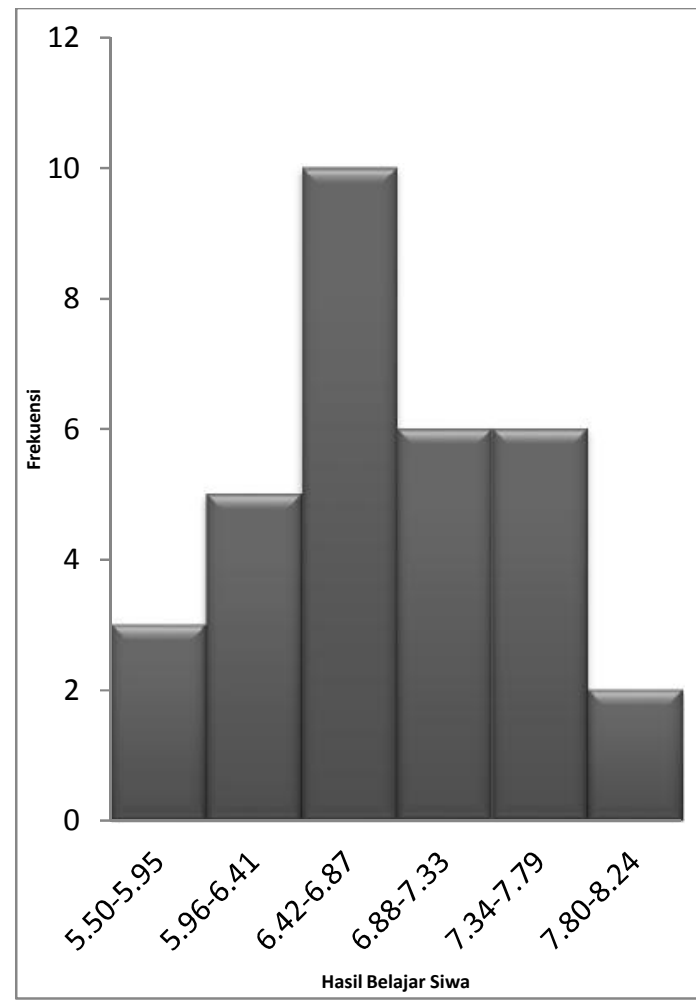

Gambar 2. Histogram Hasil Belajar

\section{B. Pengujian Hipotesis Statistik}

Tabel interpretasi koofisien korelasi $\mathrm{r}$ ( $\mathrm{r}$ tabel $=$ 0,349 ) maka dapat disimpulkan bahwa tingkat hubungan antara motivasi belajar dengan hasil belajar tergolong sangat kuat. Pada uji keberartian korelasi didapat $\mathrm{t}$ hitung $>\mathrm{t}$ tabel dengan $\alpha=0,05$. Dengan demikian dapat disimpulkan bahwa motivasi belajar siswa mempunyai hubungan yang positif dan signifikan.

Tabel 1 Ringkasan Hasil Pengujian Hipotesis Statistik

\begin{tabular}{|c|l|l|l|}
\hline $\begin{array}{l}\text { Pengujian } \\
\text { Hipotesis }\end{array}$ & \multicolumn{2}{|c|}{ Nilai } & Keterangan \\
\hline $\begin{array}{c}\text { Uji } \\
\text { korelasi }\end{array}$ & $\begin{array}{l}\text { rhitung } \\
0,860\end{array}$ & $\begin{array}{l}\text { rtabel } \\
0,349\end{array}$ & $\begin{array}{l}\text { Signifikan } \\
\text { pada } \alpha=0,05 \\
\text { dan } \mathrm{N}=32\end{array}$ \\
\hline $\begin{array}{l}\text { Eji } \\
\text { keberartian } \\
\text { korelasi }\end{array}$ & 9,1797 & 1,697 & $\begin{array}{l}\text { Signifikan } \\
\text { pada } \alpha=0,05 \\
\text { dan db }=\mathrm{n}-2 \\
\mathrm{db}=30\end{array}$ \\
\hline
\end{tabular}




\section{KESIMPULAN}

Berdasarkan analisa yang dilakukan dapat dinyatakan bahwa faktor intern yaitu motivasi belajar mempunyai pengaruh yang positif dan signifikan terhadap hasil belajar siswa. Kekuatan hubungan motivasi belajar dengan hasil belajar siswa adalah sangat kuat. Dimana korelasi (r hitung $)=0,860$ dan korelasi tabel $(\mathrm{r}$ tabel $)=0,349$ sehingga $r$ hitung $>r$ tabel. Dan $t$ hitung $=9,1797$ dan $\mathrm{t}$ tabel $=1,697$ sehingga $\mathrm{t}$ hitung $>\mathrm{t}$ tabel .

Dengan memberikan motivasi-motivasi yang kuat dan tinggi dalam pembelajaran maka akan memberikan dampak yang bersifat positif dan signifikan terhadap hasil belajar siswa SMK.. Sehingga optimalisasi tujuan belajar berupa hasil belajar siswa dapat tercapai.

\section{DAfTar Pustaka}

[1] Ahmad Arif, Jurnal Automotive Engineering Education Journals Vol 1, No 12012

[2] TIM MKDK. (2005). Bahan Ajar Belajar dan Pembelajaran. Padang : FIP UNP.

[3] Marta Eka Chandra, Jurnal Automotive Engineering Education Journals Vol 1, No 1 2012.

[4] Oemar Hamalik. (2008). Perencanaan Pengajaran Berdasarkan Pendekatan Sistem. Jakarta: Bumi aksara.

[5] Andryvo, Jurnal Automotive Engineering Education Journals Vol 2, No 12013.

[6] Ellizar Jalius. (2009). Pengembangan Program Pembelajaran. Padang : UNP Press

[7] Lufri. (2007). Kiat Memahami Metodologi dan Melakukan Penelitian. Padang: UNP Press.

\section{Biodata Penulis}

Hendra Dani Saputra, lahir di Padang Ganting, 24 Februari 1988. Sarjana Pendidikan di Jurusan Pendidikan Teknik Otomotif FT UNP 2012. Tahun 2016 memperoleh gelar Magister Pendidikan di jurusan Pendidikan Teknologi dan Kejuruan Program Pascasarjana FT UNP dengan bidang konsentrasi Pendidikan Teknik Otomotif. Staf pengajar di jurusan Teknik Otomotif FT UNP sejak tahun 2017- sekarang.

Faisal Ismet, lahir 15 Desember 1949. Sarjana pendidikan pada IKIP Padang Menamatkan Magister pendidikan di UNP. Staf pengajar di jurusan Teknik Otomotif FT UNP sejak tahun 1976- sekarang.
Andrizal, lahir 25 Juli 1965. Sarjana pendidikan pada IKIP Padang Menamatkan Magister Pendidikan Teknologi dan Kejuruan UNP. Staf pengajar di jurusan Teknik Otomotif FT UNP sejak tahun 1992- sekarang 
